\title{
Acceptance of Asthma Pharmacogenetic Study by Children and Adults
}

\section{Ann Chen Wu ${ }^{1,2,3 *}$, Robert Davis ${ }^{3}$, Kelan Tantisira ${ }^{4,5,6}$, M Maya Dutta-Linn ${ }^{1}$, Mia Hemmes ${ }^{3}$ and Scott T Weiss ${ }^{4,5,6}$}

${ }^{1}$ Center for Child Health Care Studies, Department of Population Medicine, Harvard Pilgrim Health Care Institute and Harvard Medical School, Boston, MA, USA

'Department of Pediatrics, Children's Hospital, Boston, MA, USA

${ }^{3}$ Kaiser Permanente South East, Atlanta, GA, USA

${ }^{4}$ Harvard Medical School, Boston, MA, USA

${ }^{5}$ Channing Laboratory, Department of Medicine, Brigham and Women's Hospital, Boston, MA, USA

${ }^{6}$ Center for Genomic Medicine, Department of Medicine, Brigham and Women's Hospital, Boston, MA, USA

\begin{abstract}
Background: Pharmacogenetic testing may change clinical medicine by allowing clinicians to tailor medications based on a patient's genetic makeup, however, these tests must first be validated in large, real-life populations of subjects that include children. A dearth of knowledge exists for whether pediatric populations are as willing as adult populations to provide samples for such studies.
\end{abstract}

Objective: (1) To assess whether pediatric and adult patients with persistent asthma are willing to provide specimens for DNA extraction and genetic studies. (2) To assess whether patients willingness to provide blood as compared to buccal smear specimens differ.

Methods: Of 644 patients ages 4-38 years who had three or more prescription fills for inhaled corticosteroids in one year, $60 \%$ (385) were randomized to the blood specimen group and $40 \%$ (259) were randomized to the buccal smear group in order to study acceptance of different biospecimen collection methods. Research assistants contacted subjects to obtain consent, perform a phone survey, and request a specimen.

Results: There were no baseline differences between subjects randomized to the blood specimen group versus buccal smear group with respect to age, gender, or number of dispensings of inhaled corticosteroids. Of 259 subjects in the buccal smear group, $30 \%$ (78) provided samples, and of 385 subjects in the blood specimen group, $16 \%$ (60) provided samples. Subjects randomized to the buccal smear group were more likely to provide specimens for genetic study compared to subjects randomized to the blood specimen group (RR $1.21 ; 95 \% \mathrm{Cl} 1.10-1.32$ ), even after adjusting for age. Pediatric subjects were more likely to provide specimens for genetic study than adult subjects with $23 \%(113)$ of pediatric subjects providing samples and $15 \%(25)$ of adult subjects providing samples $(p=0.03)$.

Conclusion: Children with asthma are as likely to participate in genetic studies as adults. Both children and adult subjects are more likely to provide buccal smear specimens rather than blood specimens for genetic study.

Keywords: Pharmacogenetics; Patient recruitment; Children; Buccal swab; Blood specimen

\section{Introduction}

Asthma is a major public health problem that affects almost 300 million children and adults worldwide [1]. Research on genetic testing holds special promise to improve the health of children and adults $[2,3]$. In the fast-growing field of pharmacogenetics, scant data exist on the effectiveness of pharmacogenetic testing in real-life populations. Pharmacogenetic tests currently in early testing could greatly improve asthma outcomes by allowing clinicians to tailor asthma care to individual needs. Several polymorphisms present in the gene coding for the $\beta_{2}$-adrenergic receptor (ADRB2) have been demonstrated to be associated with response to albuterol, the most commonly used rescue medication for asthma [4-8]. Furthermore, rs1876828 in the corticotrophin releasing hormone receptor 1 (CRHR1) gene has a minor allele frequency of $22 \%$ in Caucasian populations, and the presence of the minor allele has been associated with increased FEV1 following inhaled corticosteroid therapy in asthmatics [9].

Large populations of study patients from 'real-world' clinical settings are needed to study the effectiveness of pharmacogenetic tests before they can be used for clinical practice. Two main mechanisms for acquiring large enough numbers for studies of pharmacogenetic test effectiveness in large, real-world populations include creating biobanks from discarded samples $[10,11]$, which have been described in other studies, and prospective recruitment of patients, which will be the focus of this study. To our knowledge, no studies have examined the best methods for specimen collection during the prospective recruitment of pediatric patients. Blood collection through venipuncture has been the gold standard for genetic studies because several additional biomarkers can be analyzed in addition to DNA, and blood specimens provide larger quantities of high quality DNA [12]. Nevertheless, blood specimen collection can cause inconvenience for the subject because of the time needed to visit a laboratory for phlebotomy. Furthermore, parents may be less willing to allow their children to undergo the pain associated with phlebotomy. A less invasive and more convenient method of specimen collection includes obtaining buccal cells for DNA extraction [13].

A previous study suggests that African Americans are less willing to provide specimens for genetic research compared with Caucasians

*Corresponding author: Ann Wu, MD MPH, Department of Population Medicine, 133 Brookline Avenue, 6th Floor, Boston, MA 02215-5301, USA, Tel: 617-509 9823; Fax: 617-859-8112; E-mail: ann.wu@childrens.harvard.edu

Received February 20, 2011; Accepted April 02, 2011; Published April 04, 2011

Citation: Wu AC, Davis R, Tantisira K, Dutta-Linn MM, Hemmes M (2011) Acceptance of Asthma Pharmacogenetic Study by Children and Adults. Pharmacogenom Pharmacoproteomics 2:103. doi:10.4172/2153-0645.1000103

Copyright: (c) $2011 \mathrm{Wu}$ AC, et al. This is an open-access article distributed under the terms of the Creative Commons Attribution License, which permits unrestricted use, distribution, and reproduction in any medium, provided the original author and source are credited. 
[14]. Factors related to increased willingness to provide specimens for genetic research include being more educated, being nonreligious, hearing "a lot" about genetic research [15], returning research results and increasing compensation [16]. No studies have examined the willingness of parents to agree to allow their children to participate in genetic studies, whether adults or children are more likely to participate in genetic studies, or whether subjects are more likely to provide buccal smears than blood specimens.

The main objective of this study was to assess whether pediatric and adult subjects with asthma under are willing to provide specimens for DNA extraction and genetic study. We hypothesized that adult subjects would be more willing to provide specimens than parents of potential pediatric subjects because parents may be less willing to allow their children to experience discomfort related to phlebotomy or buccal smear collection. Our second objective was to assess whether subjects are more or less willing to provide blood as compared to buccal smear specimens. We hypothesized that subjects who were asked to give blood specimens would be less likely to agree to participate than subjects asked to give buccal smears because obtaining buccal smears is less invasive and can be performed by the subject or parent without travel to a phlebotomy lab. In order to answer these study questions, we chose to study asthma patients who were using inhaled corticosteroids, the most effective controller medication for asthma, because a prototype pharmacogenetic test that predicts which patients will or will not respond to inhaled corticosteroids is under active development [17].

\section{Materials and Methods}

Our study participants were drawn from a database of patients who were seen at Harvard Vanguard Medical Associates (HVMA), a multispecialty provider group in the greater Boston area. This study was approved by the institutional review board of Harvard Pilgrim Health Care and Brigham and Women's Hospital. Using our computerized database, we identified subjects between the ages of 4 and 35 years who initiated an inhaled corticosteroid between September 1, 2005August 30, 2007. We included subjects who were continuously enrolled for 10 months or more during this time period. We limited our study to patients who had at least 3 dispensings of one-month supplies of inhaled corticosteroids over the period of one year in order to select patients who were taking their controller medication most consistently. We limited our population to patients who were less than 35 years of age on September 1, 2005 to prevent likelihood of comorbid chronic conditions other than asthma and also to those over age 4 years to avoid likelihood of wheezing without a diagnosis of asthma.

Potential participants who met eligibility criteria described above were identified through the Harvard Vanguard Data Warehouse, an electronic database containing claims data of patients seen at HVMA. After notifying their primary care providers by mail, we mailed invitation letters and information to potential participants to inform them of the study and to let them know that research assistants would contact them about participation in the study. The initial mailing included an option to opt-out of receiving any further information related to the study by calling a toll-free opt-out line. Potential participants who did not optout received a telephone call from a research assistant. The research assistant explained that the goal of the study was to collect specimens for a genetic study related to asthma. The subjects were blinded to our goal to assess acceptance of the two methods of specimen collection. Potential subjects were randomized to two groups: one group was asked to provide a buccal smear specimen and the second group was asked to provide a blood specimen. Sixty percent (385) were randomized to the blood specimen group and $40 \%$ (259) were randomized to the buccal smear group. More subjects were randomized to the blood specimen group because we predicted that a lower percentage of subjects would agree to provide a blood specimen because of the time involved in going to the nearest laboratory. Participants were asked if they would be willing to complete a 5 minute telephone survey and to provide either a buccal or blood specimen based on the group to which they had been randomized. The survey included questions on race/ethnicity and questions to assess asthma diagnosis and control using the Asthma Control Test [18-20].

Participants who verbally agreed to provide buccal smears were mailed a welcome letter, consent and assent forms, and buccal smear kits with detailed instructions for collecting buccal smears. The kits were labeled with a unique study identification number and contained no direct identifiers. A research assistant called the participant after receipt of the consent form to answer questions. Once all questions were answered, participants mailed the signed consent form along with the buccal smear using prepaid postage. Upon receipt, the research assistant signed the consent form and sent a fully executed copy to the participant with a thank you letter.

Participants who agreed to provide blood specimens were also mailed a welcome letter and consent/assent forms. A research assistant called the participants after receipt of the consent forms to answer questions. Once all questions were answered, participants mailed the signed consent form using prepaid postage. Once the signed consent was received, the participants were sent a fully executed copy of the consent along with instructions to go to the laboratory at their HVMA site for phlebotomy. The blood draw involved one Paxigene tube which requires approximately $10 \mathrm{cc}$ of blood.

Participants who provided buccal smears were compensated with a $\$ 30$ gift card for their time. Participants who provided blood specimens were compensated with a $\$ 50$ gift card for their time. Patients who declined to provide buccal smear or blood specimens were asked to participate in the brief telephone interview, but were not compensated for this.

\section{Statistical methods}

Analyses were conducted in SAS version 9.1 (SAS Institute, Cary, NC, 2002-2003). We evaluated demographic factors and health utilitization variables with univariate statistics. In bivariate analyses, we evaluated whether there were differences between subjects randomized to the buccal smear group versus the blood specimen group with

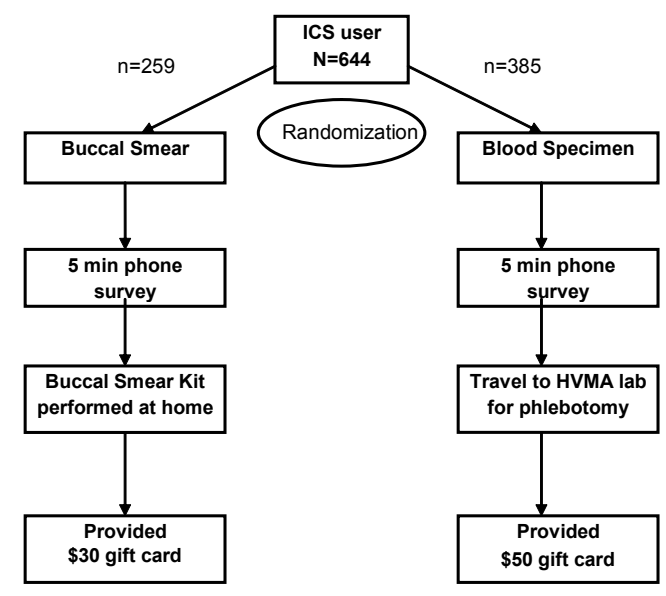

Figure 1: Flow diagram of study of eligible subjects. 
respect to independent variables which included age, sex, emergency department visits or hospitalizations for asthma. We also evaluated the association of each of our independent variables with whether or not the subject provided a specimen for genetic study. Candidate variables significant at $P \leq 0.20$ in the bivariate analyses in addition to whether the subject was an adult or pediatric subject were entered in the multivariate logistic regression to examine whether subjects randomized to the blood specimen or buccal smear groups were more or less likely to provide specimens. Candidate variables included: whether the subject was a child or adult, whether the subject was randomized to the blood or buccal smear group, the number of prescription fills of inhaled corticosteroids, number of hospitalizations and emergency department visits, and asthma control.

\section{Results}

Of 715 subjects who met our inclusion criteria based on electronic databases, $10 \%$ (71) were ineligible because they did not have asthma based on the phone interview or they did not speak English. To describe patients who stated that they were willing to provide a specimen, we use the term "cooperation rate." This is different from those who actually provided a specimen; for those subjects, we use the term "response rate." Of the 644 eligible subjects, the "cooperation rate" was $28 \%$, indicating that $28 \%$ (179) of subjects stated they were willing to provide a specimen. The "response rate," which indicates the percentage of subjects that provided a specimen, was $21 \%$ (138). More specifically, the cooperation rate for the buccal smear group was $36 \%$ (86) while the response rate was $30 \%(78)$. The cooperation rate for the blood specimen group was $19 \%(92)$ while the response rate was $16 \%(60)$.

The mean age of potential subjects at the beginning of study recruitment was 14.6 years [SD 6.8 years], 44\% (284) were female, and the age range was age $7-38$ years. We limited our study population to subjects who were age 35 years or younger when they filled a prescription for inhaled corticosteroid in 2005; thus, it was possible to be older at the time of recruitment. The mean number of prescription fills for inhaled corticosteroids was 4.8 fills in one year [SD 6.8]. Ninetynine percent of the subjects had no hospitalization for asthma during the year. Of the 208 subjects who participated in the telephone survey, $77 \%$ (90) of subjects in the blood specimen group and 68\% (62) of subjects in the buccal smear had poor asthma control based on the orally administered Asthma Control Test [19-21], $(\mathrm{p}=0.16)$. Responses to the Asthma Control Test used Likert-type rating scales and the sum yielded a score that suggested a range of control from poor to good with scores of 19 or less indicating poor control [19].

As shown in Table 1, there were no differences between subjects randomized to the blood specimen group versus buccal smear group with respect to age, gender, or number of dispensings of inhaled corticosteroids. More subjects in the buccal smear group had no emergency department visits during the study period compared to subjects in the blood specimen group ( $33 \%$ versus $14 \%, \mathrm{p}<0.0001)$.

Subjects in the buccal smear group were more likely to provide specimens for genetic analyses with $30 \%$ (78) of subjects in the buccal smear group completing specimen collection compared to $16 \%(60)$ in the blood specimen group $(\mathrm{P}<0.0001$, Table 2$)$. None of our demographic, asthma control, or health utilization variables were associated with whether or not subjects provided a specimen for genetic analysis (Table 2 ). Pediatric subjects (ages $4<18$ years) were more likely than adults to provide specimens for genetic study, with $23 \%$ (113) of pediatric subjects providing specimens compared to $15 \%$ (25) of

\begin{tabular}{|c|c|c|c|}
\hline$N=644$ & Blood Specimen Group ( $n=385)$ & Buccal smear group $(n=259)$ & p-value \\
\hline $\begin{array}{l}\text { Age (years) } \\
4-<18 \\
18-38\end{array}$ & $\begin{array}{l}73 \%(281) \\
27 \%(104)\end{array}$ & $\begin{array}{l}77 \%(200) \\
23 \%(59)\end{array}$ & 0.22 \\
\hline $\begin{array}{l}\text { Gender } \\
\text { Male } \\
\text { Female }\end{array}$ & $\begin{array}{l}57 \%(218) \\
43 \%(167)\end{array}$ & $\begin{array}{l}55 \%(142) \\
45 \%(117)\end{array}$ & 0.65 \\
\hline $\begin{array}{l}\text { No.dispensings of inhaled cc } \\
\text { in } 1 \text { year } \\
3 \\
4 \\
5 \\
6 \\
7+\end{array}$ & $\begin{array}{l}25 \%(98) \\
24 \%(93) \\
17 \%(64) \\
11 \%(41) \\
23 \%(89)\end{array}$ & $\begin{array}{l}27 \%(71) \\
26 \%(68) \\
15 \%(38) \\
9 \%(23) \\
23 \%(59)\end{array}$ & 0.85 \\
\hline $\begin{array}{l}\text { Emergency Department Visits } \\
0 \\
1 \\
2 \\
3+\end{array}$ & $\begin{array}{l}14 \%(54) \\
24 \%(91) \\
21 \%(81) \\
41 \%(159)\end{array}$ & $\begin{array}{l}33 \%(85) \\
21 \%(54) \\
15 \%(38) \\
32 \%(82)\end{array}$ & $<0.0001$ \\
\hline $\begin{array}{l}\text { Hospitalizations } \\
0 \\
1 \\
2\end{array}$ & $\begin{array}{l}98 \%(378) \\
2 \%(6) \\
0.3 \%(1)\end{array}$ & $\begin{array}{l}99 \%(257) \\
0.8 \%(2) \\
0 \%(0)\end{array}$ & 0.48 \\
\hline \multicolumn{4}{|c|}{ In 208 subjects who completed telephone interview* } \\
\hline $\begin{array}{l}\text { Race } \\
\text { Caucasian } \\
\text { Black } \\
\text { Asian } \\
\text { Other }\end{array}$ & $\begin{array}{l}63 \%(74) \\
19 \%(22) \\
7 \%(8) \\
11 \%(13)\end{array}$ & $\begin{array}{l}75 \%(68) \\
12 \%(11) \\
8 \%(7) \\
5 \%(5)\end{array}$ & 0.43 \\
\hline $\begin{array}{l}\text { Asthma Control } \\
\text { Good } \\
\text { Poor }\end{array}$ & $\begin{array}{l}23 \%(27) \\
77 \%(90)\end{array}$ & $\begin{array}{l}32 \%(29) \\
68 \%(62)\end{array}$ & 0.16 \\
\hline
\end{tabular}

*Note: Some subjects opted to complete the telephone interview even though they did not agree to provide a specimen.

Table 1: Demographics stratified by blood specimen versus buccal smear groups. 
Citation: Wu AC, Davis R, Tantisira K, Dutta-Linn MM, Hemmes M (2011) Acceptance of Asthma Pharmacogenetic Study by Children and Adults. J Pharmacogenom Pharmacoproteomics 2:103. doi:10.4172/2153-0645.1000103

Page 4 of 6

\begin{tabular}{|c|c|c|c|}
\hline$N=644$ & Provided Specimen $(n=138)$ & Did Not Provide Specimen $(n=506)$ & p-value \\
\hline $\begin{array}{l}\text { Specimen Group } \\
\text { Buccal } \\
\text { Blood }\end{array}$ & $\begin{array}{l}30 \%(78) \\
16 \%(60)\end{array}$ & $\begin{array}{l}70 \%(181) \\
84 \%(325)\end{array}$ & $<0.0001$ \\
\hline $\begin{array}{l}\text { Age (years) } \\
4-<18 \\
18-38\end{array}$ & $\begin{array}{l}23 \%(113) \\
15 \%(25)\end{array}$ & $\begin{array}{l}77 \%(368) \\
85 \%(138)\end{array}$ & 0.03 \\
\hline $\begin{array}{l}\text { Gender } \\
\text { Male } \\
\text { Female }\end{array}$ & $\begin{array}{l}23 \%(81) \\
20 \%(57)\end{array}$ & $\begin{array}{l}78 \%(279) \\
80 \%(227)\end{array}$ & 0.46 \\
\hline $\begin{array}{l}\text { No.dispensings of inhaled } \\
\text { corticosteroids in } 1 \text { year } \\
3 \\
4 \\
5 \\
6 \\
7+\end{array}$ & $\begin{array}{l}18 \%(30) \\
22 \%(35) \\
18 \%(18) \\
23 \%(15) \\
27 \%(40)\end{array}$ & $\begin{array}{l}82 \%(139) \\
78 \%(126) \\
82 \%(84) \\
77 \%(49) \\
73 \%(108)\end{array}$ & 0.27 \\
\hline $\begin{array}{l}\text { Emergency Department Visits } \\
0 \\
1 \\
2 \\
3+\end{array}$ & $\begin{array}{l}23 \%(32) \\
25 \%(36) \\
18 \%(21) \\
20 \%(49)\end{array}$ & $\begin{array}{l}77 \%(107) \\
75 \%(109) \\
82 \%(98) \\
80 \%(192)\end{array}$ & 0.50 \\
\hline $\begin{array}{l}\text { Hospitalizations } \\
0 \\
1 \\
2\end{array}$ & $\begin{array}{l}22 \%(137) \\
13 \%(1) \\
0 \%(0)\end{array}$ & $\begin{array}{l}78 \%(498) \\
88 \%(7) \\
100 \%(1)\end{array}$ & 0.72 \\
\hline \multicolumn{4}{|c|}{ In 208 subjects who completed telephone interview } \\
\hline $\begin{array}{l}\text { Race } \\
\text { Caucasian } \\
\text { Black } \\
\text { Asian } \\
\text { Other }\end{array}$ & $\begin{array}{l}72 \%(100) \\
13 \%(18) \\
7 \%(10) \\
7 \%(10)\end{array}$ & $\begin{array}{l}60 \%(42) \\
21 \%(15) \\
7 \%(5) \\
11 \%(8)\end{array}$ & 0.37 \\
\hline $\begin{array}{l}\text { Asthma Control } \\
\text { Good } \\
\text { Poor }\end{array}$ & $\begin{array}{l}29 \%(40) \\
71 \%(98)\end{array}$ & $\begin{array}{l}36 \%(16) \\
64 \%(54)\end{array}$ & 0.35 \\
\hline
\end{tabular}

*Note: Row percentages are provided rather than column percentages.

Table 2: Demographic, asthma control, and health utilization variables stratified by subjects who provided specimens versus subjects who did not provide specimens for genetic analyses.

adults ( $\mathrm{p}=0.03$ ). Adult subjects were also more likely to provide buccal smears with $22 \%$ (13) providing buccal smears and $12 \%$ (12) providing blood specimens; however this difference did not reach statitistical significance $(\mathrm{p}=0.07)$.

On multivariate analyses, subjects randomized to the buccal smear group were more likely to provide specimens for genetic study compared to subjects randomized to the blood specimen group (RR $1.21 ; 95 \%$ CI $1.10-1.32$ ). This finding was true even after adjusting for pediatric versus adult age group.

\section{Discussion}

Our study had four key findings. First, pediatric subjects are more likely to provide DNA for genetic study than adult subjects with asthma. Second, subjects are substantially more likely to provide specimens for genetic research if they are asked to provide buccal smears rather than blood specimens. Third, recruitment of patients for a genetic study from a large multi-specialty practice with excellent electronic information is feasible. Fourth, our cooperation rate was higher than our response rate in both the buccal smear and specimen groups, suggesting that some additional subjects may be willing to participate in genetic research but did not.

Our finding that pediatric subjects with asthma are just as likely to provide buccal smears or blood specimens as adult subjects was surprising. Potential reasons for this finding are that parents who agreed to provide specimens from their children for genetic studies are concerned about their children's asthma or committed to future interventions for asthma treatment. These parents may be more eager to contribute to asthma research because clinical care could be altered over the next 10 years when the children could benefit; thus these parents may be willing to have their children undergo the minimal pain associated with phlebotomy and buccal smear collection. Previous studies suggest that most parents and children are willing to participate in research that does not benefit the child but may help others [16]. Nevertheless, we hypothesized that parents may be less likely to allow their children to participate in research that involves genetics because of the negative associations connected to genetic testing, such as insurance or employment discrimination [17]. In the field of oncology, pediatric cancer patients are much more likely to be enrolled in clinical trials than adult cancer patients [18]. However, this discrepancy is thought to be secondary to differences in infrastructure of clinical care between pediatric and adult cancer patients [18].

The finding that patients are more willing to provide buccal smears than blood specimens was consistent with our hypothesis. Although previous studies have not compared recruitment of patients for buccal samples with recruitment for blood specimens in real-life populations, patients who provide buccal smears can self-collect the smears in their own home and do not have to undergo a needle-stick. These findings were robust enough to persist even in the face of unequal compensation for the two testing methods because we provided $\$ 50$ gift cards for providing blood specimens while we provided $\$ 30$ gift cards for providing buccal smears. This unequal compensation probably lessened the difference that we ended up observing. Although 28\% (179) of 
all subjects told us they would be willing to provide either a buccal or blood specimen for DNA extraction, only $77 \%$ of subjects who initially agreed to provide a specimen actually followed through with providing the specimens. Not surprising, the majority of subjects who verbally agreed to provide a specimen, but did not follow through, were randomized to the blood specimen group. Reasons for not following through with providing the specimens included the subjects' changing their mind, inability to travel to the nearest phlebotomy lab, or not feeling comfortable to decline the request from the research assistant. Although patients preferred to provide buccal smears rather than blood specimens, from the investigator viewpoint, blood specimens provide significantly more DNA, which would be needed to conduct copy number variant and methylation studies. With buccal smears, whole genome amplification may be needed, which would increase the costs for the study. Nevertheless, for most studies that seek to validate genetic associations in real-life populations, buccal smears are sufficient.

Strengths of our study include that it is a well-characterized cohort. We randomized to two approaches, buccal smear versus blood specimen groups, in order to study the willingness to participate in each group while minimizing bias. Furthermore, our study fills a gap in the literature because to our knowledge, no other studies compare methods for recruitment of real-life populations for genetic study. As pharmacogenetic testing becomes more of a possibility for clinical practice, researchers will be seeking optimal methods for recruiting subjects to provide samples for genetic studies in real-world populations. The results of our study suggest that multi-specialty practices with electronic data may be an efficient target for studying pharmacogenetic testing in real-world populations.

Despite the strengths of our study, a few limitations deserve mention. When we designed this study, blood and buccal smears were the best sources for extracting DNA in our laboratory. Since the beginning of this study, newer methods such as saliva kits (Oragene) have been shown to yield higher quantities of DNA [19]. Nevertheless, we did find that our buccal smear kits did provide ample amount of DNA. While we did not study saliva kits, we suspect that subjects would be willing to provide saliva kits at a rate that is equal to or higher than buccal smears since both approaches are relatively uninvasive and can be performed in a subject's own home by the subject. We recognize that although many genetic studies including genome wide association studies and whole exome resequencing studies can be performed with DNA extracted from buccal smears alone, many researchers may need blood specimens in order to measure other biomarkers. Furthermore, we did not study whether our response rates could have been higher had we provided gift cards with higher amounts of money. Future studies are needed to determine how to persuade subjects to provide blood specimens as opposed to buccal smears or saliva kits. We have anecdotal evidence that the extra hassle of driving to the nearest laboratory for phlebotomy may be a deterent to subjects' providing blood specimens. Thus, future studies could examine whether having a visiting nurse go to the subjects' home for phlebotomy or providing increased monetary incentive to cover gas, parking, and inconvenience associated with blood draws, could increase response rates.

Fulfilling the potential of genetic testing as a field will require an interdisciplinary approach that brings together the scientists who invent the tests with real-world populations and health care systems. Establishing large populations that are conducive to pharmacogenetic research is an important step in making predictive testing in pharmacogenetics a reality. In order to recruit a large number of subjects, researchers may achieve higher response rates by offering buccal smears (or saliva kits) rather than phlebotomy. Pediatric subjects with asthma are equally likely to participate in genetic research as adult subjects with asthma.

\section{Acknowledgments}

This study would not have been possible without Elyse Rohrer, our research assistant who worked hard to recruit subjects for this study. We appreciate the detailed data extraction conducted by Irina Miroshnik and Ruihua Yin. We would like to thank Richard Marshall MD, Director of Research at Harvard Vanguard Medical Associates, who helped facilitate this study. We are extremely grateful to our Harvard Vanguard Medical Associate collaborator, Jay Wu, MD.

\section{References}

1. Mannino DM, Homa DM, Akinbami LJ, Moorman JE, Gwynn C, et al. (2002) Surveillance for asthma--United States, 1980-1999. MMWR Surveill Summ 51 1-13.

2. Khoury MJ (2003) Genetics and genomics in practice: the continuum from genetic disease to genetic information in health and disease. Genet Med 5 261-268.

3. Cheng TL, Cohn RD, Dover GJ (2008) The genetics revolution and primary care pediatrics. JAMA 299 : 451-453.

4. Israel E, Chinchilli VM, Ford JG, Boushey HA, Cherniack R, et al. (2004) Use of regularly scheduled albuterol treatment in asthma: genotype-stratified randomised, placebo-controlled cross-over trial. Lancet 364: 1505-1512.

5. Israel E, Drazen JM, Liggett SB, Boushey HA, Cherniack RM, et al. (2000) The effect of polymorphisms of the beta(2)-adrenergic receptor on the response to regular use of albuterol in asthma. Am J Respir Crit Care Med 162: 75-80.

6. Lima JJ, Thomason DB, Mohamed MH, Eberle LV, Self TH, et al. (1999) Impact of genetic polymorphisms of the beta2-adrenergic receptor on albuterol bronchodilator pharmacodynamics. Clin Pharmacol Ther 65: 519-525.

7. Martinez FD, Graves PE, Baldini M, Solomon S, Erickson R (1997) Association between genetic polymorphisms of the beta2-adrenoceptor and response to albuterol in children with and without a history of wheezing. J Clin Invest 100 $3184-3188$.

8. Reihsaus E, Innis M, Maclntyre N, Liggett SB (1993) Mutations in the gene encoding for the beta 2-adrenergic receptor in normal and asthmatic subjects. Am J Respir Cell Mol Biol 8: 334-339.

9. Tantisira KG, Lake S, Silverman ES, Palmer LJ, Lazarus R, et al. (2004) Corticosteroid pharmacogenetics: association of sequence variants in CRHR with improved lung function in asthmatics treated with inhaled corticosteroids. Hum Mol Genet 13: 1353-1359.

10. McCarty CA, Chapman-Stone D, Derfus T, Giampietro PF, Fost N (2008) Community consultation and communication for a population-based DNA biobank: the Marshfield clinic personalized medicine research project. Am J Med Genet A 146A: 3026-3033

11. Roden DM, Pulley JM, Basford MA, Bernard GR, Clayton EW, et al. (2008) Development of a large-scale de-identified DNA biobank to enable personalized medicine. Clin Pharmacol Ther 84: 362-369.

12. Vaught JB (2006) Blood collection, shipment, processing, and storage. Cancer Epidemiol Biomarkers Prev 15: 1582-1584.

13. Le Marchand L, Lum-Jones A, Saltzman B, Visaya V, Nomura AM, et al. (2001) Feasibility of collecting buccal cell DNA by mail in a cohort study. Cancer Epidemiol Biomarkers Prev 10: 701-703.

14. Bussey-Jones J, Garrett J, Henderson G, Moloney M, Blumenthal C, et al (2010) The role of race and trust in tissue/blood donation for genetic research Genet Med 12: 116-121.

15. Henderson G, Garrett J, Bussey-Jones J, Moloney ME, Blumenthal C, et al. (2008) Great expectations: views of genetic research participants regarding current and future genetic studies. Genet Med 10: 193-200.

16. Kaufman D, Murphy J, Scott J, Hudson K (2008) Subjects matter: a survey of public opinions about a large genetic cohort study. Genet Med 10: 831-839.

17. Wu AC HB, Tantisira K, Weiss ST. Development of a pharmacogenetic test that predicts response to inhaled corticosteroids in asthma patients. Abstract 304 59 th Annual Meeting of The American Society of Human Genetics. Honolulu HI; 2009.

18. Schatz M, Mosen D, Kosinski M, Vollmer WM, O'Connor E, Cook EF, et al 
Citation: Wu AC, Davis R, Tantisira K, Dutta-Linn MM, Hemmes M (2011) Acceptance of Asthma Pharmacogenetic Study by Children and Adults. J Pharmacogenom Pharmacoproteomics 2:103. doi:10.4172/2153-0645.1000103

Page 6 of 6

(2007) Validation of the asthma impact survey, a brief asthma-specific quality of life tool. Qual Life Res 16: 345-355.

19. Schatz M, Sorkness CA, Li JT, Marcus P, Murray JJ, et al. (2006) Asthma Control Test: reliability, validity, and responsiveness in patients not previously followed by asthma specialists. J Allergy Clin Immunol 117: 549-556.
20. Nathan RA, Sorkness CA, Kosinski M, Schatz M, Li JT, et al. (2004) Development of the asthma control test: a survey for assessing asthma control. J Allergy Clin Immunol 113: 59-65.

21. Schatz M, Mosen DM, Kosinski M, Vollmer WM, Magid DJ, et al. (2007) Validity of the Asthma Control Test completed at home. Am J Manag Care 13: 661-667. 